\title{
$\mathrm{LCoS}$ 디스플레이를 이용한 파장선택스위치
}

\author{
이용민 ${ }^{1 *}$ \\ ${ }^{1}$ 선문대학교 정보디스플레이학과
}

\section{Wavelength Selective Switch using LCoS Display}

\author{
Yong-Min Lee $^{1^{*}}$ \\ ${ }^{1}$ Division of Information Display, Sunmoon University
}

요 약 본 논문은 차세대 $\mathrm{ROADM}$ 을 구성하는 핵심기술인 파장선택스위치에서 기존에 사용되는 MEMS소자 기술대신에 $\operatorname{LCOS}$ 디스플레이 기술을 적용한 파장선택스위치의 특성을 고찰한 논문이다. LCOS소자를 이용한 5 개의 포트를 갖는 파장 선택 스위치 시스템을 구성하고 응답특성과 빔제어 특성, insertion loss와 channel isolation등 파장선택 스위치로서의 기본적 인 특성들을 검토하였다. 본 파장선택스위치의 응답특성은 $11.6 \mathrm{mS}$ 로 양호하며 LCOS상에서의 grating 이미지 패턴에 따른 입사빔의 편향특성이 잘 구현되었다. C밴드내의 40개 채널에 대한 Insertion loss 측정에서 채널에 따라 $5.5 \sim 12.7 \mathrm{~dB}$ 사이의 값이 측정되었으며 인접채널간의 channel isolation 측정은 $16 \sim 18 \mathrm{~dB}$ 값이 측정되었다. 기존의 MEMS소자를 이용한 파장선 택스위치 상용화된 제품에 비해 특성은 아직 다소 부족하지만 향후 보완연구에 의해 LCOS소자를 이용한 파장선택스위치 시스템의 기술경쟁력이 충분히 확보될 것으로 기대한다.

Abstract This paper presents the characterization of the wavelength selective switch using a LCOS display instead of a MEMS device, which is a core technology for the next generation ROADM. We constructed a five-port WSS, and examined the basic characteristics of the WSS, such as the response time, beam steering, insertion loss, and channel isolation. The response time of WSS was $11.6 \mathrm{mS}$ and the beam steering characteristics of LCOS was well performed. The measured insertion loss at 40 channels in the c-band were 5.5 12.7 dB and channel isolation was $16 \sim 18 \mathrm{~dB}$. Although the characteristics of LCOS-based WSS are inferior to the conventional MEMS-based WSS, it can be improved by additional experiments that secure the technology competitiveness.

Key Words : LCOS, Optical Communication System, ROADM, WDM, Wavelength Selective Switch

\section{1. 서론}

대량의 정보를 다중파장신호로 하나의 광섬유를 통해 전달하는 wavelength-division multiplexing (WDM) [1] 전달망에서 대부분의 신호는 서로 다른 목적지를 갖고 전달되며 이 때 각 노드에서 필요한 신호를 추출(Drop) 하거나 생성된 신호를 삽입(Add) 하는 기능을 수행하는 기능이 필요한데 이런 역할을 해주는 장치를 Optical Add Drop Multiplexer $(\mathrm{OADM})$ 라고 한다.기존의 전달 망에서는 특정 노드에서 추출/삽입될 신호에 특정 파장 을 할당하는 Fixed $\mathrm{OADM}(\mathrm{FOADM})$ 고정형 방식임이므
로 특정 노드에서 트래픽 증감에 따라 할당 파장을 증가 또는 감소 시켜야 할 경우 노드에 필요한 하드웨어를 직 접 설치하고 조정해야 하므로 트래픽 양의 변화가 급격 한 상황에서 망을 효율적으로 운용하는 것이 불가능하다. 따라서 새로운 방식인 Reconfigurable $\mathrm{OADM}$ $(\mathrm{ROADM})$ [2]에서는 원격으로 추가 파장의 추출/삽입 할 수도 있고 기존 채널의 수정도 할 수 있는 장점을 갖 추게 되었다. 또한 차세대 $\mathrm{ROADM}$ 은 전송 신호의 colorless 추출/삽입을 가능하게 할 뿐만 아니라, 링과 링 의 연결 또는 메쉬 구조의 네트워크 등 자유도 3 이상인 노드에서도 활용이 가능한 가장 진보된 유연성과 효율성

본 논문은 2014년도 선문대학교 교내학술연구비 지원에 의하여 이루워졌음.

*Corresponding Author : Yong-Min Lee(Sunmoon Univ.)

Tel: +82-41-530-2349 email: ymlee@sunmoon.ac.kr

Received July 14, $2014 \quad$ Revised August 6, 2014

Accepted August 7, 2014 
을 가지고 있어 차세대 $\mathrm{ROADM}$ 시스템을 이용한 망 구 축이 본격적으로 이루어 질 것으로 예측된다.

이러한 차세대 $\mathrm{ROADM}$ 에서 핵심이 되는 노드 스위칭 기술로 Wavelength Blocker (WB), Small Switch Array (SSA), Wavelength Selective Switch (WSS), Optical Cross-Conect $(\mathrm{OXC})$ 등의 기술이 존재하는데 그중에 파 장 선택 스위치 (Wavelength Selective Switch) 기술은 일반적으로 하나의 입력 포트와 $\mathrm{N}$ 개의 출력 포트를 갖는 소자로 여러 파장으로 구성된 입력신호에서 파장 선택 스위치의 상태에 따라 특정 파장의 신호를 임의의 출력 포트로 전달 할 수 있는 장점을 갖는 소자이다. 이 파장 선택 스위치를 구성하는 핵심소자로서 Micro-Electro-Mechanical System (MEMS) 소자[3,4] 를 이용한 파장선택 스위치는 이미 개발이 완료되어 시 장을 선점하고 있으며 최근에 LCOS (Liquid Crystal on Silicon) 소자[5-7]를 이용한 파장선택 스위치 기술이 포 트확장성이 뛰어나고 부품 얼라인먼트와 견고성 등에서 유리한 장점이 있는데 아직 실용화가 미흡한 단계여서 본 연구의 주제로 삼고자 한다.

본 논문에서는 LCOS소자를 이용한 파장선택 스위치 시스템을 구성하고 응답특성과 빔제어 특성, insertion loss와 channel isolation등 파장선택 스위치로서의 기본 적인 특성들을 검토한다.

\section{2. 시스템구성 및 특성평가}

\section{1 파장선택스위치(WSS) 시스템 구성}

본연구의 대상인 파장선택스위치 시스템을 Fig. 1과 같이 구성하였다. 입력부는 5 포트를 갖는 fiber collimator array, LCOS모듈에서의 회절을 위한 편광처리부, 다중 파장으로 분리를 위한 grating lens부, 각 파장의 빔을 제 어하는 LCOS모듈로 구성된다.

Input으로 $\mathrm{LD}$ 광원이 fiber collimator array의 하나의 포트로 입사되고 $\mathrm{YVO}_{4}$ 결정과 Half Wave Plate (HWP) 를 통해서 안정적인 단일 편광이 입사되도록 한다. 입사 된 빛은 프리즘과 grating lens에서 다중 파장으로 분리 되고 collimation lens를 거쳐 LCOS 모듈에서 표시되는 이미지패턴에 따라 LCOS모듈에 입사되는 각각의 파장 은 각각 다른 각도로 반사된다. 반사된 빛은 다시 입력쪽 포트로 모아져서 fiber colimator array에서 원하는 출력
포트로 나가도록 구성하였다.

$\mathrm{LCOS}$ 소자는 통상적인 $\mathrm{CMOS}$ 반도체 제조 공정을 이용하여 이차원 적으로 배열된 화소 회로와 데이터 드 라이버, 게이트 드라이버 등 구동장치를 집적한 실리콘 웨이퍼 기판과 투명 기판사이에 액정을 주입하여 제작된 초소형 디스플레이 소자이다. 액정층의 양단에 인가되는 전압에 따라 액정층의 위상 상태가 변하는 특성을 이용 하여 입사되는 광신호가 닿는 LCOS 디스플레이 영역에 표시된 특정 이미지패턴에 따라 임의의 각도로 입사광 을 편향시켜 반사시키는 역할을 하게 된다. 일반적으로 입력되는 광신호의 구경이 단일 픽셀의 크기보다 커서 다수의 픽셀를 통해 광신호가 반사된다. 본 연구에 사용 한 사용한 LCOS 모듈은 $1920 \times 1080$ 개의 화소를 갖고 있으며 화소의 피치는 8.4um이다. LCOS의 column line 이 1920 개 임으로 40개 채널을 담당하여 스위칭 할 경우 한 채널당 48개의 column이 한 개의 채널을 담당할 수 있어 fiber에서 나오는 입력신호를 collimation lens를 통 하여 평행광을 만들었을 때 $350 \mathrm{um}$ 이상의 빔크기를 지 원할 수 있도록 하였다.

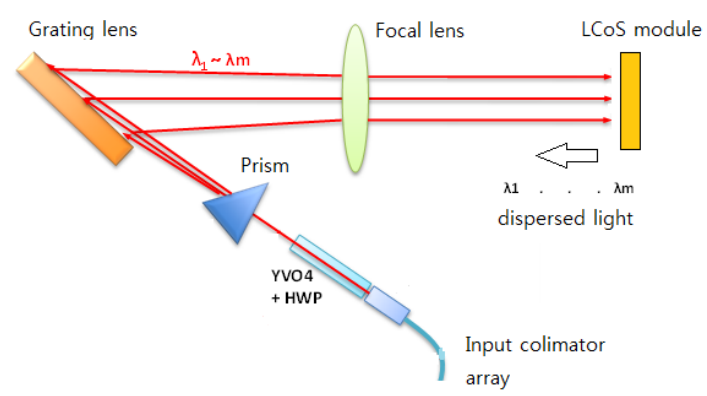

[Fig. 1] WSS system configuration

\section{2 파장선택스위치 시스템의 응답특성}

파장선택 스위치 시스템의 특성을 검증하기 위하여 Fig. 2와 같이 응답특성 측정 장치를 구성하였다. LCOS 모듈에 특정포트로 나가도록 하는 이미지패턴을 인가하 고 임의의 입력광신호를 인가하여 출력포트에 설치된 광 검출기의 신호특성을 오실로스코프로 측정하도록 구성 하였다. 이 측정 장치에서 LCOS의 모든 array에서 일정 한 phase를 갖도록 초기조건을 설정하고 입력된 광신호 가 출력포트에서 광신호가 검출 될 때까지의 시간을 측 정하여 response time을 측정하였다.

Fig. 3은 파장선택스위치 시스템의 응답특성을 오실로 
스코프로 측정한 파형을 나타낸다. 응답속도가 $11.6 \mathrm{mS}$ 로 측정되었는데 신호의 전달지연시간과 액정의 반응시간 이 합쳐져서 나타난 응답특성이다. 당초 $10 \mathrm{mS}$ 정도의 응 답특성을 기대하였고 이에 근접한 특성을 나타내어 향후 액정의 응답특성이 좀더 빠른 LCOS모듈을 사용시 충분 히 $10 \mathrm{mS}$ 이내로 달성할 것으로 사료된다.

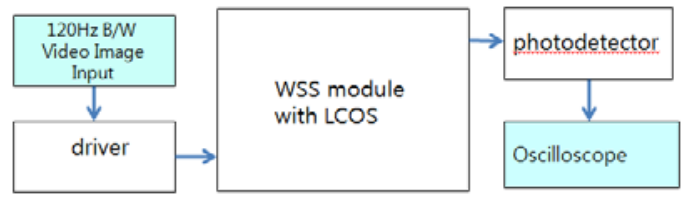

(a)

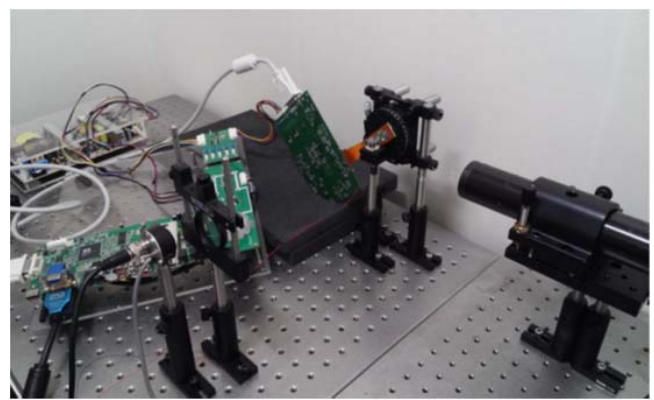

(b)

[Fig. 2] Response time measurement of WSS (a)block diagram (b)measurement setup

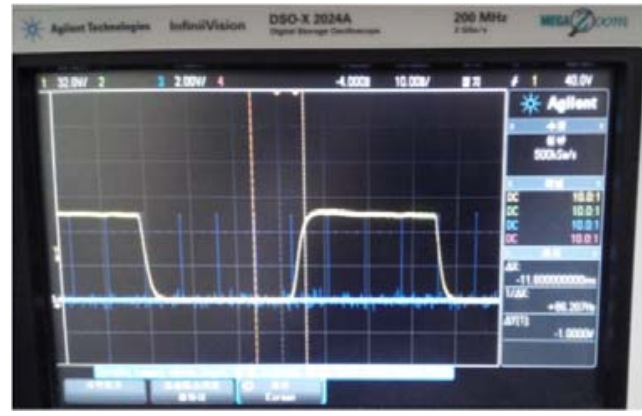

[Fig. 3] Response time measurement of WSS

\section{3 파장선택스위치 시스템의 빔제어특성}

파장선택스위치 시스템의 빔제어특성을 테스트하기 위하여 Fig. 4(a)와 같이 광원이 LCOS panel에 입사되는 각도를 $17.5^{\circ}$ 로 고정하고, 파장선택 스위치의 동작을 가 시화하기 위하여 적색 레이저 $(632.8 \mathrm{~nm})$ 를 광원으로 사 용하였다. LCOS panel상의 phase grating에 의해 steering되어 반사되는 광신호는 테스트 셋업의 후방에
위치한 스크린에 결상된다. 컴퓨터에서 생성된 phase grating pattern을 LCOS 구동회로를 통하여 LCOS panel 에 phase grating이 형성되면 phase grating의 주기에 따 라서 입사된 광신호가 선택적으로 steering되어 반사된다.

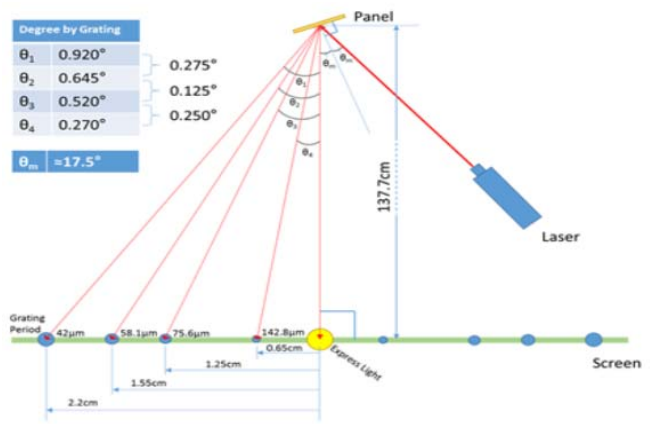

(a)

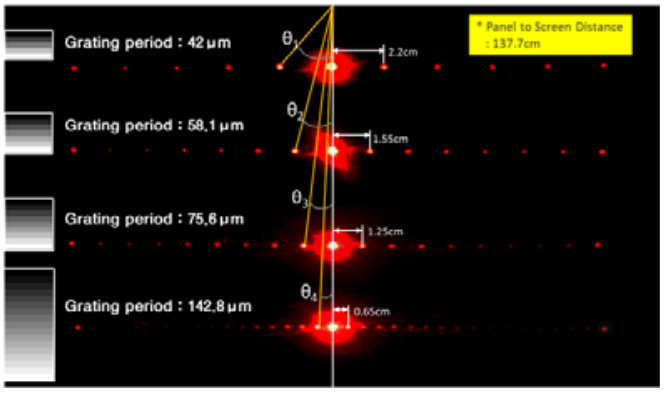

(b)

[Fig. 4] WSS beam control test

(a)block diagram of the test setup (b)steering beams on the screen

Fig. 4(b)에 나타낸 바와 같이 입사된 광신호가 LCOS panel상에 만들어지는 phase grating pattern에 따라 다 른 각도로 steering되어 반사되는 결과를 나타내었다. 테 스트 스크린에 결상된 광신호는 phase grating에 의해 steering된 것으로 여러 개의 steering 된 광이 측정되며 다수의 steering 광은 최소 회절각의 배수로 나타난다. Fig. 4(b)에서 보면 grating period 가 $42 \mathrm{um}$ 일 때 첫 번 째 광은 중앙의 express광을 기준으로 $2.2 \mathrm{~cm}$ 떨어진 위 치에 나타났고, 두 번째 세 번째 광의 위치는 각각 $2.2 \mathrm{~cm}$ 의 두배수, 세배수에 해당하는 위치에 결상하였다. LCOS panel과 테스트 스크린 사이의 거리는 $137.7 \mathrm{~cm}$ 인 것을 고려하면 $\mathrm{LCOS}$ 에 인가된 이미지 패턴상의 grating period가 $42 \mathrm{um}$ 일 때 steering 되는 각도가 $0.92^{\circ}$ 이고, grating period 가 $142.8 \mathrm{um}$ 일 때 steering 각이 $0.27^{\circ}$ 
임을 알 수 있다. Fig. 4(a)에 4개의 phase grating pattern 에 대한 각각의 steering 광의 결상 위치를 도식 하였고 그에 따른 steering 각도를 도표형태로 표시하였 다. 이와 같이 입사된 광신호가 LCOS 상의 phase grating의 period 에 따라 다른 각도로 steering 되었음을 알 수 있다.

이상의 실험결과를 바탕으로 광통신에 사용되는 C-band의 적외선 광원을 가지고 $\mathrm{LCOS}$ 상의 phase grating pattern에 따른 광신호의 steering각을 파악하여 시스템설계에 적용하였다.

\section{4 파장선택스위치 시스템의 스위칭특성}

파장분할 다중화 광전송시스템에서 사용되는 파장대 는 주로 C밴드 $\left(1528^{2} 1560 \mathrm{~nm}\right)$ 로 ITU표준채널의 21번채 널인 $1560.61 \mathrm{~nm}$ 부터 60 번채널인 $1529.55 \mathrm{~nm}$ 까지 40 개의 파장(또는 채널이라함)을 대상으로 Insertion loss와 isolation test를 실시하였다.

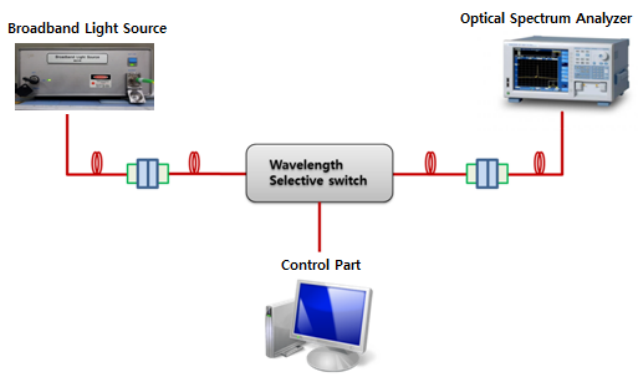

(a)

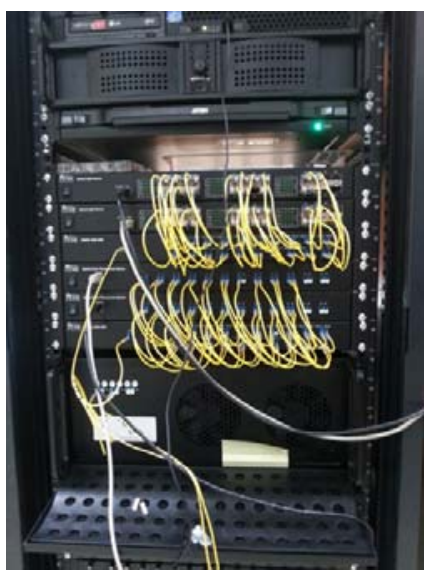

(b)

[Fig. 5] Insertion loss and isolation measurement setup (a)block diagram of the test setup (b)actual measurement setup
측정시스템 구성은 Fig. 5에 나타낸 바와 같이 전 파장 대가 나오는 Broadband Light Source(BLS)를 입력소스 로 사용하고 임의의 파장대를 어느 포트로 보낼지를 $\operatorname{LCOS}$ 모듈이 내장된 파장선택스위치 시스템에서 전자적 으로 제어한다. 그리고 Optical Spectrum Analyzer(OSA)를 이용하여 임의의 채널에서 스펙트럼 을 확인할 수 있도록 하였다.

Insertion loss 측정은 Fig. 5의 측정장치에서 파장선 택스위치 시스템에 입력되는 40 channel의 광신호가 전 부 express port와 1 4번 port 중 하나의 포트로 스위칭 되어 출력되도록 스위칭조건을 설정한 뒤 입력되는 광의 강도와 Express 포트 및 1 4번 port로 출력되는 광의 강 도를 측정하여 Insertion Loss를 계산한다. 즉 Express 포트를 포함하여 총 5 개의 출력포트에서 측정된 광의 강 도를 입력광의 강도와 비교하여 가장 낮은 광의 강도를 가지는 포트의 insertion loss를 본 파장선택스위치 시스 템의 insertion loss로 한다.

Fig. 6의 Insertion loss 측정결과를 보면 채널에 따라 $5.5 \sim 12.7 \mathrm{~dB}$ 사이의 값을 갖는 결과치를 얻었는데 기존 의 상용화제품의 경우 $6 \mathrm{~dB}$ 정도의 규격치에 비하면 좀 더 개선이 필요한 항목이다. Insertion loss값이 미흡한 원인으로 부품간의 일부 misalignment 가 영향을 줄 수 있으며 향후 부품간의 alignment를 좀 더 개선하고 LCOS모듈의 향상된 anti-reflection 코팅처리, Erbium Doped Fiber Amplifier (EDFA) 등을 도입하여 Insertion loss값을 좀 더 개선하는 실험이 가능할 것이다.

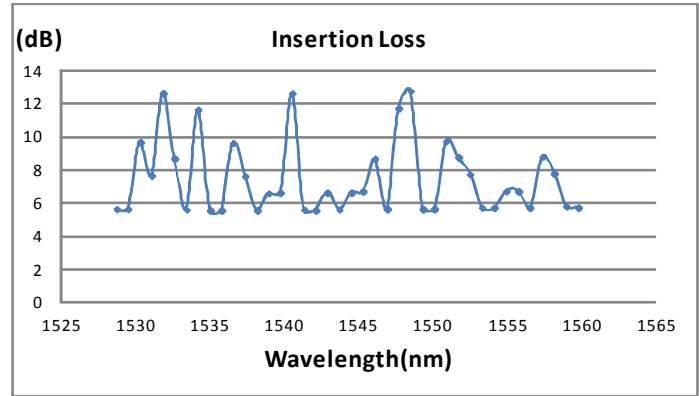

[Fig. 6] Measurement of insertion loss

Channel isolation 항목은 통상적으로 인접된 채널에 서 crosstalk이 많이 일어나므로 임의의 채널로 광이 출 력될 때 출력되지 않아야 할 인접채널에서의 광의 강도 를 측정하여 channel isolation 특성을 파악한다. Fig. 5 의 
측정장치에서 파장선택스위치에서 채널 $1,3,5,7$ 로 광이 출력되도록 조건을 설정하고 채널 $2,4,6,8$ 에서 광신호 를 측정한다. 반대로 파장선택스위치에서 채널 $2,4,6,8$ 로 출력되도록 조건을 설정하고 채널 $1,3,5,7$ 에서 광신 호를 측정을 반복한다. 5 개의 출력포트에서 측정된 결과 를 Table 1 에 나타내었다.

측정된 결과가 $16 \sim 18 \mathrm{~dB}$ 로 파장선택스위치 상용화 제품의 통상적인 channel isolation기준치인 $25 \mathrm{~dB}$ 보다 는 아직 낮은 수준이지만 충분히 실용화 가능성이 있는 channel isolation특성을 확인하였다.

[Table 1] Measurement of channel isolation

\begin{tabular}{c|c|c}
\hline port number & $\begin{array}{c}\text { odd channel } \\
(\mathrm{dB})\end{array}$ & $\begin{array}{c}\text { even channel } \\
(\mathrm{dB})\end{array}$ \\
\hline \hline port 1 & 17.08 & 17.85 \\
\hline port 2 & 18.21 & 17.74 \\
\hline port 3 & 17.78 & 18.22 \\
\hline port 4 & 17.99 & 15.78 \\
\hline port 5 & 16.45 & 18.13 \\
\hline
\end{tabular}

\section{5 실험결과 고찰}

본 파장선택스위치 시스템의 응답속도는 $11.6 \mathrm{mS}$ 로 측정되었는데 시스템상의 신호전달 지연시간과 액정의 응답시간이 합쳐진 결과이다. 시스템상의 신호전달 지연 시간을 개선하기보다는 액정의 응답속도가 빠른 액정물 질을 채용한 $\mathrm{LCoS}$ 모듈을 입수하여 실험을 진행한다면 좀더 빠른 시스템의 응답속도를 기대할 수 있다. 또한 본 파장선택스위치 시스템의 빔제어특성의 steering각 실험 결과는 적색 레이저광 $(632.8 \mathrm{~nm})$ 입력을 사용하여 얻은 결과이며 실제 광통신에서 사용하는 C-band 파장의 광 원사용시는 steering 회절각도가 본 실험의 결과치와 약 간 달라진다는 사실을 인지하고 시스템설계를 하여야 한다.

\section{3. 결론}

본 연구에서는 LCOS모듈 기술을 응용한 파장선택 스 위치 시스템을 구성하고 응답특성과 빔제어 특성, insertion loss와 channel isolation 특성 등을 검토하였다. 현재의 MEMS소자를 이용한 파장선택스위치 상용화된 제품에 비해 특성은 아직 부족하지만 LCOS모듈을 이용 한 파장선택스위치 시스템의 실용화 가능성을 충분히 보
였다. 향후 추가적인 연구를 통해 부품간의 alignment개 선, LCOS모듈의 향상된 anti-reflection 코팅처리, EDFA 도입실험 등을 통해 성능향상이 되면 파장선택 스위치 기술로 경쟁력을 충분히 확보할 것으로 기대한다.

\section{References}

[1] S. Sugimoto, K. Minemura, and K. Kobayashi, "High-speed digital-signal transmission experiments by optical wavelength-division multiplexing," Electronics Letters, vol.13, no.22, pp.680-682, 1977

DOI: http://dx.doi.org/10.1049/el:19770482

[2] M. Feuer, D. Kilper, and S. Woodward, "'ROADMs and their system applications"" in Optical Fibre Telecommunications VB, (I. Kaminov, T. Li., A. Willner eds), pp. 293-343, San Diego, Academic Press, 2008

[3] M. C. Wu, O. Solgaard, and J. E. Ford, "Optical MEMS for lightwave communication," "J. Lightw. Technol., vol. 24, pp. 4433-4454, 2006

DOI: http://dx.doi.org/10.1109/JLT.2006.886405

[4] D.M. Marom, D.T. Neilson, D.S. Greywall, C.-S. Pai, N.R. Basavanhally, V.A. Aksuyuk, D.O. Lopez, F. Pardo, M.E. Simon, Y. Low, P. Kolodner, C.A. Bolle, "Wavelength-selective $1 \mathrm{~K}$ switches using free-space optics and MEMS micromirrors: theory, design, and implementation," J. Lightw. Technol. 23 pp. 1620 -1630, (April) 2005

DOI: http://dx.doi.org/10.1109/JLT.2005.844213

[5] N. Collings, T. Davey, J. Christmas, D. Chu, and B. Crossland, "The applications and technology of phase--only liquid crystal on silicon devices," J. Display Technol., vol. 7, no. 3, pp. 112 - 119, 2011 DOI: http://dx.doi.org/10.1109/JDT.2010.2049337

[6] O. Gerstel, M. Jinno, A. Lord, and S. J. Ben Yoo, "Elastic optical networking: A new dawn for the optical layer," IEEE Commun. Mag., vol. 50, pp. S12-S20, 2012 DOI: http://dx.doi.org/10.1109/MCOM.2012.6146481

[7] M. Johansson, S. Hard, B. Robertson, I. Manolis, T. Wilkinson, and W. Crossland, "Adaptive beam steering implemented in a ferroelectric liquid crystal spatial-light-modulator free-space, fiber-optic switch," Appl. Opt., vol. 41, no. 23, pp. 4904--4911, 2002 DOI: http://dx.doi.org/10.1364/AO.41.004904 
이 용 민(Yong-Min Lee)

[정회원]

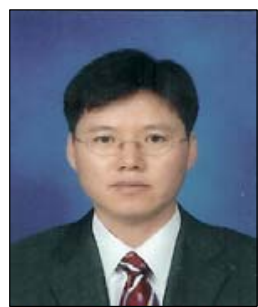

- 1986년 2월 : 인하대학교 전자공학 과 (공학사)

-2005년 1월 : Univ. of Edinburgh 전자공학과(공학박사)

-1985년 12월 2007년 2월 : 삼성

$\mathrm{SDI}$ 수석연구원

-2008년 3월 현재 : 선문대학교 정보디스플레이학과 부교수

<관심분야>

디스플레이, 광통신소자, 터치패널 구동기술 